\title{
The evolving role of a clinical instructor in an integrated undergraduate nursing curriculum
}

\author{
Amanda O'Rae , Jennifer Langille, Aaron Li, Kara Sealock, Gayle Rutherford \\ Faculty of Nursing, University of Calgary, Calgary, Alberta, Canada
}

Received: July 14, 2016

Accepted: September 19, 2016 Online Published: November 29, 2016

DOI: $10.5430 /$ jnep.v7n4p87

URL: http://dx.doi.org/10.5430/jnep.v7n4p87

\begin{abstract}
Undergraduate nursing curriculum is changing to keep pace with the healthcare system. As a result, nursing faculties must consider innovative approaches to clinical instruction. In 2010, one nursing faculty transformed the traditional sessional clinical instructor role into a Nursing Practice Instructor role in order to facilitate the integration between theory and practice in both on and off campus settings. This descriptive qualitative study involved conversational interviews led by Nursing Practice Instructor peer-researchers to elicit the perceptions of how roles have changed from that of a sessional instructor. Eligibility for participation included all Nursing Practice Instructors who previously held a role as a sessional instructor in the same faculty. Data Analysis was done using a content analysis approach where themes within each guiding question were identified and then compared for congruency and further interpretation. Participants felt that there were differences between the sessional Clinical Instructors and Nursing Practice Instructor roles and expectations and as a result of this change, they were more invested in their teaching role based on their ability to integrate the curriculum, the opportunity to engage in the faculty, and contribute to student learning in a more significant way. Overall, the Nursing Practice Instructor role has initiated changes in how clinical instructors are employed and supported, contributing positively to the outcomes associated with an integrated, context-relevant curriculum, and ultimately, fostering future nurses with the ability to make a difference in the healthcare system.
\end{abstract}

Key Words: Clinical instructor, Practice education, Integrated curriculum, Descriptive qualitative research

\section{INTRODUCTION}

Clinical teaching in baccalaureate nursing education has long been acknowledged as "the heart of the educational program for nursing" ${ }^{[1]}$ (p. 505). As early as the 1940s, experts recommended that clinical teachers should have a larger role within the overall teaching program. ${ }^{[2]}$ The role of the clinical instructor in Canadian nursing education has evolved over time. Historically, an experienced registered nurse employed in a hospital setting carried out the majority of clinical instruction; however, with the establishment of university based nursing programs, this role has relocated into academic institutions. $^{[1,3]}$
Wong and Wong ${ }^{[1]}$ proposed that clinical teaching in a university program does not receive the same kind of recognition as other intellectual pursuits, causing faculty members to shun this activity. For several decades, graduate nurses filled this void by taking on sessional or part-time faculty appointments. This was especially true after 1960 when substantial changes in general post-secondary education saw basic, graduate, and continuing education programs for nurses expand in size, scope, and resources. ${ }^{[4]}$ Nursing education experienced another major shift in the 1990s when a 4-year baccalaureate degree, rather than a 2-year diploma, was viewed as the minimum entry-to-practice required for new registered nurses. ${ }^{[5]}$

*Correspondence: Amanda O’Rae; Email: aorae@ucalgary.ca; Address: Faculty of Nursing, University of Calgary, Calgary, Alberta, Canada. 
At this time, the newly combined classroom and clinical instruction led to the increased need for registered nurses to teach clinical practice. Strategies to teach clinical practice in a degree program have also evolved, leading to a need to refine the clinical instructor role.

In 2010, a Faculty of Nursing in a western Canadian university introduced a revised undergraduate curriculum that emphasized context-relevant integrated learning. ${ }^{[6]}$ This transformation saw a concurrent change to various facets of the traditional sessional clinical instructor role into a Nursing Practice Instructor (NPI) role. The role changed to facilitate the integration between theory and practice, whereby the NPIs played a key role in integrating learning both on and off campus. The contract required that NPIs be knowledgeable of the program design and curriculum through engagement in teaching, scholarship, and service responsibilities to support an integrated, context-relevant curriculum. However, with no evidence in the literature to support the development of a clinical instructor role within an integrated, contextrelevant curriculum we leveraged an opportunity to explore this transition.

In this paper, we will present the findings from a small descriptive qualitative study on integration of the NPI role into the nursing faculty. Of particular interest is how NPIs perceived the differences in the role specifically related to teaching responsibilities, development and delivery of the curriculum, and being included in a team.

\subsection{Study context}

\subsubsection{Curriculum revisions}

The Carnegie Foundation for the Advancement of Teaching promotes an integrated learning approach in undergraduate nursing education as a means to account for the reality of practice today. ${ }^{[7]}$ This educational approach prepares learners to make connections across complex contexts and develop the attributes to be responsive, lifelong learners through a focus on the learning process. ${ }^{[7]}$ An integrated curriculum threads practice, competencies, and context through each course and across every term and utilizes a safe on campus learning environments to support integrative thinking over time. ${ }^{[8,9]}$ In order for nursing faculty members to support this learning, they require preparation related to the curriculum, expertise in content area, ability to role model decision making processes, and the capacity to apply knowledge to the clinical setting while remaining current with practice changes. ${ }^{[8]}$

In response to nursing education recommendations, one western Canadian university shifted the focus of the nursing curriculum away from an over-emphasis on content to a more balanced focus on relevance (salience), clinical reasoning, and nursing action in particular situations and contexts. Benner et al. ${ }^{[8]}$ suggested that the needed changes could take place through the integration of classroom and clinical teaching using both curricular and teaching innovations. The revised NPI's role was an integral component of these program changes.

\subsubsection{Clinical instructor role change}

The role description and expectations of the clinical instructor evolved to best facilitate changes to the program's philosophy, purpose and objectives. The clinical instructors needed increased awareness of both program and semester design, and to be positioned to participate in both the curriculum development and teaching innovation that would support the revised curriculum. The clinical instructor needed to create a supportive learning environment for students enrolled in the new program to enable integration of learning specifically related to theory and practice. The NPI role enables the instructor to be better connected with the faculty as a whole and provides opportunities to cultivate the knowledge and skills necessary to connect and reinforce salient parts of student learning.

Previously, clinical instructors were hired only under sessional contracts term-by-term. NPIs were hired on part-time or full-time limited-term agreements ranging from one to two years. The NPI role was structured as a limited-term academic appointment with a workload assignment proportioned as 80 percent teaching, 10 percent service and, 10 percent scholarship based on a 1.0 FTE. The rationale for this modification was to provide opportunities for the NPIs to fulfil the expectations of the new curriculum and become integrated as a member of the faculty. First, the NPIs would become knowledgeable of both the overall program and curriculum by attending team and faculty meetings, as well as other faculty service events to build relationships and collegiality within the greater faculty. In addition, NPIs would be provided opportunity to engage in scholarship to develop their teaching and instructional skills. Lastly, NPIs were required to facilitate learning opportunities that integrated theory and practice by teaching in both on-campus (in a lab setting) and off-campus (in a hospital or community) learning environments.

Overall, the introduction of these NPI expectations required the faculty to change its hiring process and contractual terms of employment for their clinical instructors. The intention of this contractual change was to enable NPIs to meet role expectations by being more involved in the faculty. A number of past sessional instructors were hired into NPI positions, presenting a timely opportunity to learn their perceptions of 
the evolving clinical instructor role and its relationship to the substantively revised nursing program.

\section{MeTHODS}

\subsection{Design}

This study used a descriptive qualitative design to explore the transition from a sessional instructor role to an NPI role. According to Sandelowski, ${ }^{[10]}$ qualitative descriptive designs provide a thorough examination of a specific event that draw from the "general tenets of naturalistic inquiry" (p. 337). The phenomenon of study becomes an accurate representation of the lifeworld of the participants. Descriptive qualitative design allowed the researchers to identify commonalities from interviews to enhance new knowledge of this phenomenon. Through an interpretive analysis, the intent of the study was to better understand the lived experience of NPIs, offering new knowledge of this phenomenon and impact for nursing education.

\subsection{Sample}

All NPIs who previously held a role as a sessional instructor in the Faculty of Nursing were eligible to participate in this study. An invitation, study information, and an informed consent were emailed to all 30 eligible instructors. A follow-up reminder was emailed, and interested participants were asked to email the administrative assistant. Overall, 11 NPIs who taught across the entire curriculum agreed to participate in the study. Their experience as a sessional clinical instructor ranged from 4 months to more than 20 years, and their NPI experience ranged from 5 months to 2 years.

\subsection{Data collection}

In the context of this study, both participant and researchers were nurses and instructors at same educational institution. It was important to ensure that a member of the research team who did not work in the same semester interviewed each participant. Information derived from the interviews provided an opportunity for textual analysis and interpretation of the lived experiences from each participant. Individual conversational interviews were conducted between September 2012 to January 2013. Each interview lasted 10 to 42 minutes and was conducted at a convenient place for the participant. The semi-structured interview guide was designed to elicit perceptions about how their role changed from a sessional instructor to an NPI, incorporation of on-campus teaching, and their relationship with other members of the faculty. All interviews were audio recorded and transcribed verbatim by a professional transcriptionist.

Published by Sciedu Press

\subsection{Data analysis}

We used a content analysis approach ${ }^{[11]}$ where themes within each guiding question were identified and then compared for congruency and further interpretation. Initially, each member of the research team independently read the transcripts to formulate provisional themes that coincided with our guiding questions. Under each question, information was narrowed down to general themes based on the perceptions of the researcher. One researcher imported all transcripts into NVivo 9 as a tool for thematic comparison. As a team, each transcript was additionally reviewed and general themes were furthered discussed. Specific themes were identified through comparison of the NVivo 9 themes in order arrive at consensus. The final additional review was to ensure trustworthiness of the emerging themes within the information. ${ }^{[12]}$

\subsection{Ethical considerations}

This study received ethical approval from the Research Ethics Board [E-24781]. Before each interview, the interviewer reviewed the consent form with the participant before the participant signed it. All interviews were audio recorded and transcribed verbatim. Any identifying information was removed from the transcripts and prior to analysis. Only the investigators of the study, the project coordinator, and the transcriptionist had access to the raw data. All data was safely stored in a locked cabinet or password protected computers.

\section{Results}

Results from the conversational interviews suggest that participants felt there are differences between the sessional clinical instructors and NPI roles and expectations. As a result of the terms of employment associated with the new role, participants perceived they were more invested in their teaching role as evidenced by their ability to integrate the curriculum, the opportunity to engage in the faculty, and contribute to student learning in a more significant way. Overall, the study revealed four primary strengths of the new NPI role but also revealed three challenges of the new role as a key player in an integrated curriculum.

\subsection{Strengths}

\subsubsection{Ability to integrate the curriculum}

The participants identified that a significant change to the NPI teaching role was the expectation to bridge theory and practice in both on- and off-campus settings. This change required the NPI to have a greater awareness of the curriculum and the trajectory of learning across the program. As a sessional instructor, this had been a challenge due to limitations in knowledge of the curriculum; "I had little knowledge of the curriculum as a whole when I was a sessional instructor" (participant 12). 
The NPIs were provided an orientation to the overall curriculum when first hired followed by a term-specific orientation each semester; "I never had an orientation of that length (1 week) with being a sessional" (participant 4). Participant 6 stated, "It would have been really nice when I first started teaching to have... an orientation that we did as Nursing Practice Instructor." This provided NPIs with an opportunity to work with other faculty and to be more aware of what students learn from one course to another, and from one term to another. NPIs knew what to expect from their students and how to bridge learning in the practice setting with theory courses. "I need to also have a very good understanding of what's happening in other courses" (participant 3). This awareness was created through the opportunities to work on campus with other faculty members, attend meetings related to the curriculum, and engage in development opportunities.

\subsubsection{Relationships with students}

The participants commented that the on-campus teaching requirements provided an additional opportunity to work with the students and build relationships in small groups of 7 to 16 students. "I have a better perspective of where the students are coming from and what I should expect out of my students" (participant 7). In addition to knowing what the students had learned and what they were going to learn, NPIs were able to know their students better, since they were spending more time with students in multiple teaching and learning practice settings, as well as instructing in different terms.

\subsubsection{Faculty engagement}

Participants noted that their relationships with other faculty members had changed as a result of the NPI role; "as a sessional I didn't feel like I was part of faculty" (participant 1). Specifically, their relationships had grown as a result of the opportunities to attend regular meetings and faculty development events, on campus teaching assignments, as well as having a physical working space on campus. Participants also formed relationships with other NPIs, with increased feelings of support and a sense of inclusion amongst NPIs and course coordinators. It was noted that as a sessional this was not the case: "it was like you would just show up and maybe not even be on site because you're out in the clinical and not ever really feel a part of it all" (participant 4). "I think as a sessional... I would just come and go and I wasn't that involved in, um, meetings as much" (participant 2).

In addition, the role change enabled NPIs to identify mentorship opportunities with other faculty; participant 7 stated, "there's also much more integration of Nursing Practice Instructor with the actual faculty." The increase in their awareness of who teaches specific courses, and ability to identify administrative resources available to support them in their role were also evident: "I have more of a role now in actually developing things" (participant 1).

\subsubsection{Impact of the terms of employment}

Participants commented on the new contractual changes. Their limited term contracts as a NPI extended beyond a semester, which increased their sense of commitment and created a sense of job satisfaction. "I feel that I have more sense of commitment because I know that I'll be here for 2 years and contributions are valued as opposed to being a sessional instructor... for that 13 weeks" (participant 3). Adding to the positive changes seen in the NPI contract, eligibility to receive health benefits was an incentive. Many participants became more interested in completing a master's degree to advance their careers and to engage in the scholarship expectations associated with a fulltime contract. This focus on scholarship within the limited term contract was perceived as a positive change in the role.

\subsection{Challenges}

Although, the contract and terms of employment created many positive differences between sessional instructor and NPI positions, some challenges unique to the new role have surfaced and pre-existing issues were not eliminated.

\subsubsection{Availability to students}

Although all participants viewed that the on-campus teaching requirement was beneficial to build relationships with students, this role expectation added an additional time commitment: "A lot more lesson planning, a lot less time to deal with our students and support our student in that way" (participant 10). NPIs noted that a significant amount of time was required to prepare for on-campus teaching, thus, affecting the availability to meet with students outside of assigned clinical hours.

\subsubsection{Value and recognition as a member of the team}

While many participants noted the benefit of faculty engagement, some participants questioned if other faculty valued the NPIs. Some NPIs were uncertain whether the changes in faculty relationships extended beyond the greater connection with other NPIs to improved relationships with the remainder of the faculty members. "I' $m$ not so sure from a nursing practice instructor perspective if... that relationship (with faculty) is what it needs to be or how it could be improved" (participant 12). Participants attributed the varying relationship outcomes to possible ambiguity about the role change. Moreover, the NPIs' physical workspace was separate from the rest of the faculty, which contributed to feeling disconnected from the rest of the faculty members. 


\subsubsection{Employment and terms of contract}

NPIs felt that contract commitments made it difficult to stay current with practice, given scheduling and workload issues. "I need to also pick up shifts and keep up my skills and I find that difficult to do [as an NPI]" (participant 3). Several NPIs also felt that because they were paid salary, the hours of actual work do not translate into a competitive hourly pay for a registered nurse. Further, the nature of the academic schedule and the workload also made it more challenging to take earned vacation.

I found that [teaching three semesters] was a long time teaching without being able to take any vacation time, because the only vacation time that we were allowed was during Christmas and New Year's... but you have to remember that if we're hired elsewhere we pick up shifts during that time... that was really stressful. (Participant 6)

Some participants noted that although role orientation was indepth, some areas of the NPI contract expectations, such as opportunities for advancement in this role, were not clear and required further orientation after the initial hiring processes.

\section{Discussion}

We need to understand how to best prepare nurses for the faculty role, ${ }^{[13,14]}$ but to date, the perspectives of clinical instructors on their own role is limited. ${ }^{[15]}$ Results from this descriptive qualitative study address this gap in the literature and suggest that NPIs saw differences between sessional clinical instructors and NPI roles and expectations. Participants perceived that the integrated curriculum had significantly modified the teaching role of NPI and their terms of employment. These changes contributed to how they were able to integrate the curriculum and build relationships with both faculty and students. This role was identified as having some contractual challenges, however, this did not seem to shift the perception of value for clinical instruction.

\subsection{Curriculum integration}

Integrating faculty within clinical and classroom teaching can assist students to develop knowledge to bridge the theory and practice gap. ${ }^{[7]}$ The new nursing curriculum at a western Canadian university attempted to narrow this gap by fully integrating NPIs into on campus and off campus teaching environments. Participants of this study commented that their role increased their sense of responsibility as instructors they were required to be more knowledgeable of the entire curriculum not just their current teaching assignment.

Participants detailed that the greater awareness of the curriculum gained from the integrated curriculum, the introduction of the NPI role, along with faculty support for their role enabled them to better integrate theory and practice for their students. Experts in the field of nursing education have purported that clinical instructors are key in bridging the gap between theory, research, and practice. ${ }^{[15,16]}$ Landers $^{[14]}$ identified the potential for nursing faculty, who were classroom and clinical experts, to bridge the theory-practice gap. She noted that these nursing faculty members could guide students in the practice setting as well as enhance their application of theory. Finn, King, and Thorburn ${ }^{[17]}$ conducted focus groups and administered questionnaires with 40 part-time clinical instructors in Australia and found they all commented that their lack of knowledge on the curriculum was a barrier to bridging theory and practice.

Traditionally, clinical instructors spend 1 to 2 days per week with students in a practice setting. With the integrated curriculum, instructors spend increased time with students with the combination of practice setting time and on-campus time in a laboratory learning environment. Customarily, due to limited time with students, clinical instructors will present information that is specific and focused to the area in which they are teaching, often viewing skills as separate tools for practice. ${ }^{[18]}$ This places the responsibility on the students to integrate their recently attained theoretical knowledge into practice. Our data demonstrated that with their shift in role, NPIs were more aware of what the students were learning in both theory and practice and were able to support them in transitioning their theoretical knowledge into their practice. Further study will be required to truly understand the correlation between the NPI role, the integrated curriculum, and reducing the theory/practice gap.

\subsection{Relationships with students}

As noted in 4.1, in an integrative curriculum, instructors work with students in the lab setting to help them learn required skills before moving into the practice setting where the instructors work with the students as they provide care. This connected relationship supports co-participation in the learning process, where students are more at ease, feel valued, and respected. ${ }^{[19]}$ When teachers have the time to get to know their students, they are better able to support their learning and are better able to support their learning needs. ${ }^{[19]}$ Teacher competence is another aspect that lends to building the relationship between the student and the teacher. ${ }^{[19]}$ Knowing the curriculum and being an integral part of how it is delivered helps to build that competence and confidence as a clinical instructor.

NPIs welcomed more opportunity to build relationships with students and contribute more significantly to their learning. Other study findings also indicated that clinical instructors believed that they need to be a role model and source of sup- 
port to students. ${ }^{[20,21]}$ In an American qualitative study consisting of interviews with 21 adjunct clinical faculty, nurse clinicians who were hired on a semester-to-semester basis, participants saw their clinical educator roles as coaching students, providing a safe learning environment, and guiding them in their learning. ${ }^{[14]}$ With more time with students, student-instructor relationships can develop and grow and student are more easily supported and challenged in their ways of thinking — students are more at ease and encouraged to ask questions. ${ }^{[18]}$ Gillespie $^{[19]}$ discussed the importance of the student-instructor connection and how this relationship can positively influence students' clinical learning experience. These relationships support learning by developing students' clinical judgment, communication, and organizational skills. ${ }^{[19]}$ As instructors develop a trusting relationship with students, they are better able to recognize and identify the individual student's learning needs. ${ }^{[19]}$ Students value getting to know their instructors through the sharing of their own stories as nurses, watching them interact with other professionals, and interactions with patients. ${ }^{[19]}$ Given our integrative curriculum and the increased time spent teaching students, many NPIs discussed how they were able to get to know, support, and challenge their students in a way not possible with the past traditional curriculum.

\subsection{Faculty engagement}

The NPIs in this study described the relationship growth with other faculty members, a sense of inclusion, and increased feelings of support on campus. Limited connections between clinical instructors and the academic environment in which they teach may negatively affect identifying with academic goals and effectively developing their clinical teaching role. ${ }^{[22]}$ In the study by Roberts et al. ${ }^{[14]}$ participants viewed feeling connected to the academic institution was viewed as important, though many felt a lack of connection, possibly due to their short-term contracts. Some of these participants felt they were not perceived to be full members of the faculty since their role was only temporary and that they were hired to fill in spots such that other faculty members could fulfil their other academic roles in scholarship and teaching. ${ }^{[14]}$ In our study, the feeling of disconnect was more commonly felt as a sessional instructor; while the orientation and other faculty events contributed to a sense of inclusion for NPIs.

In the current study, opportunities to have a mentor or a teaching partner, particularly in the on-campus learning environment, were seen as extremely helpful to NPIs. A recent literature review on the clinical instructor role in nursing education examined the facilitators and constraints to effective clinical instruction. ${ }^{[15]}$ Overall, the review concluded that while clinical instructors deemed university support (both formal and informal) valuable, there was a lack of tangible support and resources for clinical instructors to learn how to be effective in clinical education. In another study, clinical instructors spoke favourably about having a mentor especially in difficult situations or in dealing with student issues. ${ }^{[14]}$ Formal orientation delivered by key faculty members can help to establish connections early on whereby mentoring or coaching relationships can be established to support new faculty. ${ }^{[23]}$ The relationships formed are a factor that supported retention of clinical instructors in their roles. ${ }^{[3]}$ Ongoing opportunities for faculty to connect and discuss their teaching experiences improves collegiality and can even stimulate scholarly activity. ${ }^{[24]}$ For the NPIs, sharing an office space also facilitated informal support networks among clinical instructors that were transitioning into an academic role. However, the participants in this study were uncertain about their relationship with other members of the broader academic community with whom they had less opportunity for interaction.

\subsection{Value and recognition as a member of the team}

The instructors in this study questioned their value as a member of the larger faculty team. Although unfamiliarity of the clinical instructor role among the greater faculty may have contributed to participants' feelings, the faculty's historical perceptions of value of the clinical instructor's role likely influenced this outcome. While clinical teaching is recognized as a significant component of nursing education, historically it has not received the same recognition and value as other academic pursuits, which can create a divide between faculty members. ${ }^{[1,4,25,26]}$ Oermann ${ }^{[25]}$ described clinical teaching as the "invisible' faculty, contributing to feelings of not being valued" (p.333). Despite challenges unique to clinical teaching, large classroom teaching may still be recognized as more significant to nursing education. ${ }^{[25]}$ In contrast to the clinical setting, where the skills as a clinician are extremely valued and recognized, the academic setting often gives more merit to research capacities. ${ }^{[29]}$ When many clinical instructors lose confidence in their expertise as they transition to teaching roles, an environment that further questions one's worth perpetuates negative feelings toward the work environment. $^{[3]}$

Schriner ${ }^{[26]}$ suggested that academia must consider how to value the competency that clinical instructors exhibit in the midst of the traditional academic culture of reward. In their review of healthy workplaces for nursing faculty and staff, Fontaine, Koh, and Carroll ${ }^{[27]}$ acknowledged meaningful recognition as a standard for a healthy workplace, requiring that "faculty must be recognized and must recognize others for the value each brings to the work of the organization" ( $p$. 
561). At an administrative level, full faculty involvement in decision making about establishing the faculty's common values builds a sense of ownership and creates a supportive teaching culture; further, ongoing opportunities for faculty to connect and discuss teaching improves collegiality. ${ }^{[24]}$ Strategies that bring clinical instructors and other faculty together could increase visibility for all roles and emphasize the value that each faculty member brings to institution.

\subsection{Employment and terms of contract}

The NPI's in this study described both positive and negative aspects of having longer-term contracts. Under sessional contracts, the clinical instructor had limited orientation, restricted time with students, and a narrowed scope of teaching materials. The change to the role of the nursing instructor enabled opportunities for informal mentorship, increased involvement with planning, and established administrative resources available for support and to mitigate issues related to burnout and emotional exhaustion. In depth orientation and training was part of the terms of employment and further opened opportunities for positive forms of support for teaching. Disch, Edwardson, and Adwan ${ }^{[28]}$ found that key sources of satisfaction were being a member of the workplace team, an effective communication system, constructive feedback from colleagues, and supportive networks. Holopainen, Hakulinen-Viitanen, \& Tossavainen ${ }^{[29]}$ analyzed studies of nurse teacher jobs and the majority of the findings indicated that positive relationships with students and support from colleagues and management increased job satisfaction. Student contact and professional autonomy had strong effects with job satisfaction. ${ }^{[30]}$ The time and flexibility built within the terms of the NPIs' contracts allowed some opportunity for both increased student contact, support from colleagues and management.

Many studies of job satisfaction of nursing educators examined both extrinsic and intrinsic factors. ${ }^{[31,32]}$ There was no clear consensus of whether intrinsic factors were more important than extrinsic factors in affecting employment attraction and retention. Plawecki and Plawecki ${ }^{[32]}$ found that intrinsic factors, such as personal satisfaction of the work itself, were more important than extrinsic factors such as pay. The study by Marriner and Craigie ${ }^{[31]}$ noted the opposite. A Moody ${ }^{[33]}$ study found that the addition of extrinsic factors such as eligibility to receive benefits, opportunities to advance in rank and promotion, and length of annual contract ranged from neutral to positive predictors to job satisfaction. Both intrinsic and extrinsic factors have added to the NPI terms of employment. With the inconsistent evidence of the level of impact, extrinsic and intrinsic variables have on job satisfaction further study will be needed to determine the full

Published by Sciedu Press extent of the impact of the terms of employment on the NPI role.

\subsection{Study limitations}

There were limitations to this study. This was a small study conducted in the early implementation of this new curriculum and the new role of the NPI. The new curriculum has now been in place for three years since data collection for this study. We believe that if we were to conduct the interviews again at this time, that new data may surface adding further depth to our findings.

This study occurred with a specific target group and at one location. There were specific requirements for participants, which limited the numbers of participants. The location of the space allocated for NPI offices separate from the main faculty may have also influenced the NPI responses and perceptions and may have presented an anomaly in our findings. The physical spaces may have influenced how NPI's felt and valued the work, the level of connection to others, and the impact it had for teamwork and collaborative relationships. Research team members were peers of the participants and some also participated in the study. This may have led to subjectivity, however, this may have increased the credibility of the study as it provided the ability for the researchers to understand the study from a relational level, discover new knowledge, and confront assumptions. ${ }^{[15]}$

\subsection{Further research}

Further research will be required to explain the unanswered questions from the study, such as the impact of the physical spaces as well as the effects of the role change on NPI job satisfaction and retention. In addition, further study is needed on the extrinsic and intrinsic factors contributing to the retention of the NPI. Knowing the effects of physical workplaces and the values that had significant impact of retention could help understand and create a formula for a positive workplace, learning, and teaching environment.

\section{Conclusion}

The innovative NPI role contributed to successfully implementing a context-relevant integrated curriculum. The modification to the contract and terms of employment has provided the framework for NPIs to be engaged in the integration of the curriculum in practice through their teaching responsibilities. On-campus teaching improved opportunities to bridge theory and practice, contributing to stronger relationships with students. The modification to roles and expectations has prompted the nursing faculty to provide more extensive role orientation and specific opportunities to become familiar with the curriculum and contribute to its de- 
velopment. This role has required teaching and professional development as well as faculty engagement and mentorship opportunities, which all contribute positively to the perceptions of those employed as an NPI. Efforts to address the negative perceptions of salary, flexibility to take vacation, workload issues, and the value of this position amongst the entire faculty need to be considered in order to fully support this role change. Overall, NPIs feel their contracts and terms of employment encourage commitment to their position and the overall change in role has sparked investment to continue as members of the faculty. This study indicates that NPIs feel that they are contributing to the preparation of nurses by supporting the integration of classroom and clinical teaching, strengthening the ability of future registered nurses to address the current realities of the health care system.

\section{CONFlicts OF InTEREST Disclosure}

The authors declare that there is no conflict of interest.

\section{REFERENCES}

[1] Wong J, Wong S. Towards effective clinical teaching in nursing. Journal of Advanced Nursing. 1987; 12: 505-513. http://dx.doi.o $\mathrm{rg} / 10.1111 / \mathrm{j} .1365-2648.1987 . \mathrm{tb} 01360 . \mathrm{x}$

[2] Stewart FM. The education of nurses: Historical foundations and modern trends. New York: MacMillan; 1945.

[3] Duffy R. Nurse to educator? Academic roles and the formation of personal academic identities. Nurse Education Today. 2013; 33: 620-634. http://dx.doi.org/10.1016/j.nedt.2012.07.020

[4] Vollman AR. The clinical instructor of nursing and the learning environment: A qualitative study. [Dissertation]. [Ottawa, ON]: University of Ottawa; 1990.

[5] Vande Griend T. Novice nursing clinical instructors: The lived experience. [thesis]. [Lethbridge, AB]: University of Lethbridge; 2011.

[6] Rosenau P, Watson L, Vye-Rogers L, et al. Educating for complexity in nursing practice: A baccalaureate curriculum innovation Quality Advancement in Nursing Education. 2015; 1(3): Article 4. http://dx.doi.org/10.17483/2368-6669.1039

[7] Benner P, Sutphen M, Leonard V, et al. Educating nurses: A call for radical transformation. San Francisco: Jossey-Bass; 2010.

[8] Lim AG, Honey M. Integrated undergraduate nursing curriculum for pharmacology. Nurse Education in Practice. 2006; 6: 163-168 http://dx.doi.org/10.1016/j.nepr.2005.11.005

[9] Dickieson P, Carter LM, Walsh M. Integrative thinking and learning in undergraduate nursing education: Three strategies. International Journal of Nursing Education Scholarship. 2008; 5(1): 1-15 http://dx.doi.org/10.2202/1548-923X.1696

[10] Sandelowski M. Whatever happened to qualitative description? Research in Nursing and Health. 2000; 23: 334-340 http://dx.doi.org/10.1002/1098-240X (200008)23: 4<334: : AID-NUR9>3 . 0. CO;2-G

[11] Hsieh HF, Shannon SE. Three approaches to qualitative content analysis. Qualitative Health Research. 2005; 15(9): 1277-1288. http://dx.doi.org/10.1177/104973230527668

[12] Barker J. Evidence-based practice for nurses. (2nd ed.). Thousand Oaks: Sage; 2013.

[13] Bell-Scriber MJ, Morton AM. Clinical instruction. Train the trainer Nurse Educator. 2009; 34(2): 84-87. http://dx.doi .org/10.10 97/NNE. Ob013e31819ae753

[14] Roberts KK, Kasal CS, Flowers C. The perceived needs of nurse clinicians as they move into an adjunct clinical faculty role. Journal of Professional Nursing. 2013; 29(5): 295-301. http://dx.doi.o $\mathrm{rg} / 10.1016 / \mathrm{j}$. profnurs . 2012.10.012

[15] Dahlke S, Baumbusch J, Afflect F, et al. The clinical instructor role in nursing education: A structured literature review. Journal of Nursing
Education. 2012; 51(22): 692-696. http://dx.doi.org/10.39 28/01484834-20121022-01

[16] Whalen KS. Work-related stressors experienced by part-time clinical affiliate nursing faculty in baccalaureate education. International Journal of Nursing Education Scholarship. 2009; 6(1): Article 30. http://dx.doi.org/10.2202/1548-923X.1813

[17] Finn T, King J, Thorburn J. The educational needs of part time clinical facilitators. Contemporary Nurse. 2000; 9: 132-139. http: //dx.doi.org/10.5172/conu.2000.9.2.132

[18] Valiga TM. Nursing education trends future implications and predictions. Nursing Clinics. 2012; 4: 423-434. http://dx.doi.org/1 $0.1016 / j$. cnur.2012.07.007

[19] Gillespie M. Student-teacher connection in clinical nursing education. Journal of Advanced Nursing. 2002; 37(6): 566-576. http: //dx.doi.org/10.1046/j.1365-2648.2002.02131.x

[20] Duffy K, Watson HE. An interpretive study of the nurse teacher's role in practice placement areas. Nurse Education Today. 2001; 21: 551-558. http://dx.doi.org/10.1054/nedt. 2001.0582

[21] Heshmati-Nabavi F, Vanaki Z. Professional approach: The key feature of effective clinical educator. Nurse Education Today. 2010; 30: 163-168. http://dx.doi.org/10.1016/j.nedt. 2009.07.010

[22] Andrew S, Halcomb EJ, Jackson D, et al. Sessional teachers in a BN program: Bridging the divide or widening the gap? Nurse Education Today. 2010; 30: 453-457. http://dx.doi.org/10.1016/j.ned t.2009.10.004

[23] Gazza EA, Shellenbarger T. Successful enculturation: Strategies for retaining newly hired nursing faculty. Nurse Educator. 2005; 30(6): 251-254. http://dx.doi.org/10.1097/00006223-200 511000-00009

[24] Feldman KA, Paulsen MB. Faculty motivation: The role of a supportive teaching culture. New Direction for Teaching and Learning. 1999; 78: 71-78. http://dx.doi.org/10.1002/tl.7807

[25] Oermann MH. Role strain of clinical nursing faculty. Journal of Professional Nursing. 1998; 14: 329-334. http://dx.doi.org/10. 1016/S8755-7223(98) 80074-4

[26] Schriner CL. The influence of culture on clinical nurses transitioning into the faculty role. Nursing Education Perspective. 2007; 28(3): 145-149. PMid: 17557636

[27] Fontaine DK, Koh EH, Carroll T. Promoting a healthy workplace for nursing faculty and staff. Nursing Clinics of North America. 2012; 47: 557-566. http://dx.doi.org/10.1016/j. cnur.2012.07.008

[28] Disch J, Edwardson S, Adwan J. Nursing faculty satisfaction with individual, institutional and leadership factors. Journal of Professional Nursing. 2004; 20: 323-331. http://dx.doi .org/10.1016/j.p rofnurs.2004.07.011 
[29] Holopainen A, Hakulinen-Viitanen T, Tossavainen K. Nurse teacherhood: Systematic descriptive review and content analysis. International Journal of Nursing Studies. 2007; 44(4): 611-623. http: //dx.doi.org/10.1016/j.ijnurstu.2006.04.004

[30] McHale, C. Job mobility among nurse teachers. Nursing Standard. 1991; 6: 30-32. https://dx.doi.org/10.7748/ns.6.1.30.s 47

[31] Marriner A, Craigie D. Job satisfaction and mobility of nursing educators. Nursing Research. 1977; 26(5): 349-359. http://dx.doi
. org/10.1097/00006199-197709000-00007

[32] Plawecki JA, Plawecki HM. Factors that influence attraction and retention of qualified nurse educators. Nursing Research. 1976; 25(2): 133-135. http://dx.doi .org/10.1097/00006199-197603000 $-00013$

[33] Moody NB. Nurse faculty job satisfaction: A national survey. Journal of Professional Nursing. 1996; 12(5): 277-288. http://dx.doi.o $\mathrm{rg} / 10.1016 / \mathrm{s} 8755-7223(96) 80007-\mathrm{x}$ 